\title{
The Rising Tide of Overweight among Kuwaiti Children: Study from Al-Adan Hospital, Kuwait
}

\author{
Fawaz Abdullah Al-Refaee $^{a}$ Shaima A. Al-Qattan ${ }^{b}$ Shahira M. Jaber ${ }^{b}$ \\ Alyah A. Al-Mutairi $^{\text {b }}$ Sarah S. Al-Dhafiri ${ }^{b}$ May Fouad Nassar ${ }^{c}$ \\ Departments of a Pediatrics, and ${ }^{b}$ Food and Nutrition, Al-Adan Hospital, Ministry of Health, Kuwait City, Kuwait; \\ 'Department of Pediatrics, Faculty of Medicine, Ain Shams University, Cairo, Egypt
}

\section{Key Words}

Body mass index $\cdot$ Child health $\cdot$ Overweight

\begin{abstract}
Objective: This study was designed to screen patients who sought medical services in the Pediatric Outpatient Department, Al-Adan Hospital, Kuwait for overweight. Subjects and Methods: Body mass index (BMI) was used to screen 361 children ( $\leq 10$ years old) for risk of overweight and overweight (BMI between 85 th and 94 th, and $\geq 95$ th percentile, respectively). Overweight children were fully examined and abdominal ultrasound was done for each of them. Results: Of the 361 children, 52 (14.41\%) and 77 (21.33\%) were at risk of overweight and overweight, respectively. There was a slight male predominance for overweight ( 40 males, $51.95 \%$, compared to 37 females, $48.05 \%$ ) and within the overweight category; 28 males (70\%) and 26 females (70.27\%) were above 6 years of age. In overweight children over 6 years, 4 (7.41\%) had hepatomegaly with fatty changes and 3 (5.56\%) had blood pressure above the 95th percentile for age and sex. Conclusion: Childhood overweight at Al-Adan Hospital was high and increased with age. Hence childhood screening for overweight is recommended at an early age because it is an important risk factor of chronic diseases.
\end{abstract}

Copyright ๑ 2013 S. Karger AG, Basel

\begin{tabular}{ll}
\hline KARGER & $\begin{array}{l}\text { (c) 2013 S. Karger AG, Basel } \\
1011-7571 / 13 / 0226-0600 \$ 38.00 / 0\end{array}$ \\
E-Mail karger@karger.com & $\begin{array}{l}\text { This is an Open Access article licensed under the terms } \\
\text { of the Creative Commons Attribution-NonCommercial- } \\
\text { www.karger.com/mpp }\end{array}$ \\
& $\begin{array}{l}\text { NoDerivs 3.0 License (www.karger.com/OA-license), appli- } \\
\text { cable to the online version of the article only. Distribution } \\
\text { for non-commercial purposes only. }\end{array}$
\end{tabular}

\section{Introduction}

Studies in various countries have shown increases in the prevalence of overweight among children in recent years [1]. Childhood obesity has become a public health epidemic with 22 million children below the age of 5 affected [2]. Even during the pediatric age, obesity is associated with cardiovascular risk factors such as dyslipidemia, high blood pressure and metabolic syndrome. Luckily it is a preventable risk factor and success has been reported simply by lifestyle changes on a family basis [3]. In 2005, the US Preventive Services Task Force found adequate evidence that body mass index (BMI) was an acceptable measure for identifying children and adolescents with excess weight [4]. This study was designed to screen patients who sought medical services in the Pediatric Outpatient Department at Al-Adan Hospital, Al-Ahmadi Governorate, Kuwait for overweight using the BMI percentiles.

\section{Subjects and Methods}

All children 10 years old or younger who sought medical services for minor illnesses at the Pediatric Outpatient Department of Al-Adan Hospital, Kuwait during the month of March 2012 were included in the study. Patients who had chronic illnesses or were on chronic medications such as steroids that would likely affect
Dr. Fawaz Abdullah Al-Refaee

Head of the Gastroenterology, Hepatology and Nutrition Unit Pediatric Department, Al-Adan Hospital, Ministry of Health

Kuwait City (Kuwait)

E-Mail dralrefaee@gmail.com 
their anthropometric measurements were excluded from the study. A total of 560 patients were recruited, 57 were excluded due to inaccuracy in data collection. Of the 503 patients screened, 142 were younger than 2 years of age and were thus excluded since the screening method, BMI, is interpreted using children's BMI percentile charts that do not include children younger than 2 years of age [5]. Hence 361 children (166 girls and 195 boys) were enrolled in the study.

For each studied case, both weight and height were measured. Body weight was measured to the nearest $50 \mathrm{~g}$ using a regularly calibrated scale with the subject lightly clothed. A special board calibrated in centimeters and millimeters was used to measure height to the nearest $0.5 \mathrm{~cm}$ with the subject barefoot. BMI was calculated as: $\mathrm{BMI}=$ weight in $\mathrm{kg} /$ height in meters ${ }^{2}$. BMI values were used to determine a percentile score on the basis of the population-based references developed by the Centers for Disease Control and Prevention in 2000. Classification into underweight (BMI $<5$ th percentile), normal (BMI between 5th and 84th), risk of overweight (BMI between 85th and 94th) and overweight (BMI $\geq 95$ th percentile) was done according to Skelton and Rudolf [6], who stated that though the terms overweight and obesity are used interchangeably, overweight is the preferred term in children and adolescents. For cases of proven overweight, blood pressure was measured with complete clinical examination as well as abdominal ultrasound in cases with hepatomegaly.

\section{Statistical Analysis}

The collected data was coded, tabulated, and statistically analyzed using SPSS program (Statistical Package for Social Sciences, version 17). Descriptive statistics were done for categorical data by number and percentage. The prevalence rate for each item was calculated as the number of cases per 100 children; $\chi^{2}$ test was used to compare frequency of qualitative variables among males and females. For comparisons a probability (p) less than 0.05 was considered significant.

\section{Results}

Of the 361 studied children, 52 (14.41\%) were at risk of overweight, 77 (21.33\%) were overweight, 46 (12.74\%) were underweight, while $186(51.52 \%)$ had normal weight. There was an equal female-to-male ratio for risk of overweight with a slight male predominance for overweight (40 males, $51.95 \%$, compared to 37 females, $48.05 \%$ ) with no statistically significant differences detected among them $(\mathrm{p}<0.05)$. Age distribution showed that 54 overweight children $(70.13 \%)$ were above 6 years of age $(28$ male overweight children, $70 \%$, and 26 female overweight children, $70.27 \%$ ), while a total of 23 overweight children (29.87\%) where below 6 years of age.

Among overweight children over 6 years, 4 (7.41\%) had hepatomegaly with fatty changes as detected by ultrasound and 3 (5.56\%) had blood pressure above the 95 th percentile for age and sex. Complications were not detected in patients younger than 6 years of age.

\section{Discussion}

The $21.33 \%$ overweight reported in the current study is higher than the $18.4 \%$ overweight and $16.7 \%$ obesity previously reported among Al-Ahmadi governorate students [7]. This discrepancy can be attributed to the fact that our series is bigger and contains a wider age range (the previous study included only 5 th grade students who are 10 years old while our study included children $2-10$ years old). However, the percentage of overweight detected in the current study is close to that reported as a crisis, which currently affects nearly one third of American children and adolescents aged 2-19 years [8].

The percentage of overweight in our sample of children increased with age and showed a slight male predominance. These results are consistent with the US Preventive Services Task Force and Barton [9], who reported that the prevalence of obesity varied with age and was more likely to be higher in older than younger children and in males. Although the US Preventive Services Task Force did not find sufficient evidence for screening children younger than 6 years, the current study reported that $29.87 \%$ of cases occurred before the age of 6 years. Since many of these children could continue as such throughout late childhood to adolescence when complications of obesity are more evident, we suggest that screening starts at a younger age.

The hepatomegaly with fatty changes detected by ultrasound in $7.41 \%$ of the studied overweight children over 6 years is reinforced by the results of Babusik et al. [10], who recently reported that abdominal obesity had an independent predictive value for developing liver steatosis among adults in Kuwait.

\section{Conclusion}

The prevalence of childhood overweight at Al-Adan Hospital was high and increased with age. Hence childhood screening for overweight is recommended at an early age because it is an important risk factor of chronic diseases. 


\section{References}

$>1$ Krebs NF, Jacobson MS: American Academy of Pediatrics Committee on Nutrition. Prevention of pediatric overweight and obesity. Pediatrics 2003;112:424-430.

2 World Health Organization (WHO): Global Strategy on Diet, Physical Activity and Health: Obesity and Overweight. 2005. [http://www. who.int/dietphysicalactivity/strategy/ eb11344/strategy_english_web.pdf]. Accessed July 2012.

-3 Schwandt P, Bertsch T, Haas GM: Sustained lifestyle advice and cardiovascular risk factors in 687 biological child-parent pairs: the PEP Family Heart Study. Atherosclerosis 2011; 219:937-945.
4 Whitlock EP, Williams SB, Gold R, et al: Screening and interventions for childhood overweight: a summary of evidence for the US Preventive Services Task Force. Pediatrics 2005;116:e125-e144.

5 Kuczmarski RJ, Ogden CL, Guo SS, et al: 2000 CDC Growth Charts for the United States: methods and development. Vital Health Stat 11. 2002;246:1-190.

6 Skelton JA, Rudolf CD: Overweight and Obesity; in Behrman RE, Kliegman RM, Jenson HB, Stanton BF (eds): Nelson Textbook of Pediatrics; ed 18. Philadelphia, Saunders Elsevier, 2008, chap 44.

7 Abdelalim A, Ajaj N, Al-Tmimy A, et al: Childhood obesity and academic achievement among male students in public primary schools in Kuwait. Med Princ Pract 2012;21: 14-19.
Ogden CL, Carroll MD, Kit BK, et al: Prevalence of obesity and trends in body mass index among US children and adolescents, 19992010. JAMA 2012;307:483-490.

$>9$ US Preventive Services Task Force, Barton M: Screening for obesity in children and adolescents: US Preventive Services Task Force recommendation statement. Pediatrics 2010; 125:361-367.

10 Babusik P, Bilalb M, Durisc I: Nonalcoholic fatty liver disease of two ethnic groups in $\mathrm{Ku}$ wait: comparison of prevalence and risk factors. Med Princ Pract 2012;21:56-62. 